\title{
Socio-cultural Context and Theological Sources of the Modern European Science Formation: Theoretic-Methodological Ideas and Approaches
}

\author{
Konstantin Viktorovich Vodenko \\ Elena Yurevna Polozhenkova
}

Tamara Petrovna Matyash

Darya Nikolaevna Burmenskaya

\section{Ludmila Alexandrovna Shvachkina}

Don State Technical University, 344000, Rostov-on-Don, pl. Gagarin, 1, 8; Email: vodenko-kv@rambler.ru

Doi:10.5901/mjss.2015.v6n5s3p99

\section{Abstract}

In the article the comparative analysis of the main methodological ideas and approaches to a problem of a Socio-cultural context and Christian and philosophical sources of the genesis of the modern European science is carried out. It is shown that according to S. Yaki's concept, Christian Catholicism in which the Creator's cult based on the cosmological argument was systematically emphasized was the religion, which created optimum conditions for the development of science. The Protestant hypothesis of $M$. Weber - R. Merton differs in a reduction of the analysis of religious terms of emergence of science to features of a Puritan way of life, and data of specifics of science to simply to the interpreted experimentalism. Similar the "method from conditions" does not give the chance of an explanation of substantial transformations of the bases of antique and medieval science, which led to formation of the bases of the modern European natural sciences. The conclusion that the method of "absolute metaphysical prerequisites" of R. J. Collingwood allows to reveal Christian theological "the postulates functioning as contexts" which being excremental in outlook of founders of classical science of Modern times is drawn, had impact on the content of their scientific ideas. It is noted that the considered theoretical-methodological approaches do not mutual denial and, on the contrary, complement each other.

Keywords: science, religion, culture, society, Christianity, theology.

\section{Introduction}

The appeal to the declared subject is caused by some the circumstances connected with functioning of science and some effects of scientific and technical progress in the modern world. First, destructive ecological and sociocultural effects of scientific and technological advances in the XX century cause criticism of scientism understanding of its place and assignment in human lives, societies, and nature. However, implementation of the antiscience program with its nihilistic relation to science threatens the European culture with the loss of its major case as scientific rationality. In this regard for its preservation, there is need of internal transformation of scientific reason in the way of its rapprochement with other forms of spiritual experience, first with religion and philosophy. Secondly, in the conditions of post non-classical science subjective activity of the scientist, it's valuable and target structures, metaphysical, religious, moral beliefs closely correspond to the nature of the gained knowledge of the object. The specified features of modern science define, in our opinion, the importance of searches of interrelations between religion and scientific knowledge of social epistemology.

The historical and genetic aspect of the ratio of science and religion is the object of research of this article, the methodology of studying of Socio-cultural context and Christian and philosophical sources of the formation of classical science - its subject. Respectively the purpose of work consists in the identification of well-being context and theoreticmethodological ideas and approaches of research of Christian and philosophical sources of the modern European science. However, whether there is sense to consign so far to the past, addressing to science sources. Reflecting on this question, the modern American historian of theology and science S. Yaki truly notices that "studying of any subject demands, first of all, approach to it from the point of view of its embryonic state, it belongs and to science. The incorrect understanding of sources with inevitability leads to the false conclusions and concerning all subsequent steps" (Yaki, 1993, p. 239). In other words, identification of religious sources of the modern European science can help, in our opinion, 
with understanding of its today's problems and contradictions, and also specifics of its ratio and interrelations with religion at the present stage.

Specifics of the declared subject define the methodological basis of work. Along with hermeneutic procedures in the article, the method of comparative analysis is widely used. Besides, in work the dialectic principles of research are applied: historicism, concreteness of consideration, and also methods of the analysis, synthesis, generalization along with other classical general logical and methodological procedures.

\section{Catholic Hypothesis of S. Yaki}

Recognition of the special role of Christian dogma information of classical, modern European science in the western historiography and methodology of science has happened enough recently - only from the middle of the XX century, in post-war decades. R. Merton, R. J. Collingwood, A. Koyre, E. Klaaren, Ch. Webster, S. Mason, S. Yaki, A. Whitehead and other researchers, developed this subject to a varying degree. Until the specified time as the modern domestic philosopher of science V. N. Katasonov notes, " deadening formal positivistic interpretations of history of science, "revolutionary" opening of "scientific revolutions" could not catch this theological component in the history of formation of the systems of knowledge which have led to today's science" (Katasonov, 1997, p. 142). Separate works, for example, the in-depth studies of P. Dyugem devoted to this subject on medieval cosmology, remained almost unnoticed.

Recognition of certain deep correlations between classical science and Christian dogma is initiated by judgment of that fact that creators of the modern European science - Galilei, Descartes, Bacon, Boyle, Newton, Pascal, Leibniz were sincerely believing people identifying the outlook as Christian. Thus, the judgment of this fact causes some questions, which in the course of our research it is necessary to answer. First, why the Christianity is connected with the genesis of science, but not any other, for example, one of East religions? Secondly, if the correlation of classical natural sciences with Christianity is not accidental what of the existing Christian theological systems promoted its formation? At last, in - the third, whether the range of religious premises of this process is settled only by Christian sources?

In this regard the modern American historian of science and the Catholic theologian S. Yaki formulates question as follows: "why only once in the history of mankind, in 1250-1650 in Europe scientific researches have got mature forms, and of them it became possible to speak as about science in the true sense of the word. Involuntarily there is thought of Christianity as about that religion that promoted the emergence of the natural-science relation to the world" (Yaki, 1993, p. 237).

At this S. Yaki comes to a conclusion about the incompatibility of East religions with science owing to the originality of those cultural conditions, both in India and in China, which are defined by specifics of these religious beliefs. According to the logic of the American researcher, religion the dominating role in forming of culture belongs, and then the culture can promote the emergence of science. However, if the science has arisen, it is identical to any cultures. In this regard, commenting on the point of view Yaks, not concordant with Koyre and Kuhn's anti-cumulativist views, the domestic philosopher of science L. A. Markova notices: "From here also rejection Yaks of revolutions results: no fundamental changes in development of science can be, it is homogeneous" (Markova, 1997, p. 224).

The American researcher and, first of all, with need "the theoretical generalization conducting to formulation of quantitative laws" refers idea of recurrence, pantheism, sociomorphism, contemplation to characteristics of the ancient Eastern cultures that are not coordinated with criteria of scientific knowledge. The idea of recurrence of development, widespread and in Ancient India, and in ancient China did not fit into scientific outlook in which ideas of infinite space and the unidirectional time prevailed. Pantheistical view of the universe as uniform organism in which the person is it is small insignificant part, does not give it the chance to look at the world from the outside that is essence of the subject and object relations, characteristic for natural-science research of the nature. Besides the idea of recurrence and the pantheistical description of space-generated confusion in logic, destroying the idea of the clearness of relationships of cause and effect.

Transferring of laws of life of society on development of the nature, characteristic for sociomorphism, interfered with forming of understanding of the world as objective and arranged, namely such it appeared in consciousness of great founders of the modern European science. At last, the sermon of the contemplate, passive relation to nature obviously was not agreed with energetic of experimental natural sciences. As a result, S. Yaki, it is explicit from Eurocentric positions, pronounces sentence to east science, defining science stories in China, India, Egypt as "deadlock" or "dead born branches". Proceeding from the recognition of self-sufficiency of East cultures and originality of their cognitive traditions, it is hardly possible to agree with its conclusion. It is rather possible to claim that the science of West European type could not arise in cultural and historical conditions of the ancient East.

At the same time, the fact of the uniqueness of the modern European science demands special research of its 
specific sources. From the point of view of the American researcher, Christian Catholicism was the religion that created optimum conditions for the development of science. He emphasizes that though fundamentals of all monotheist religions are worship the Creator of the Universe, nevertheless, between them there is an essential distinction. This distinction is "that measure in which purely rational view of the Universe can become a source of recognition of the existence of the Creator" (Yaki, 1993, p. 237). Thus, the natural theology that purpose is the rational knowledge of the Creator on his creations, owing to certain reasons did not gain development either in Judaism nor in Moslem. In Christianity it "could not enjoy popularity in East Orthodoxy where attachment to monastic and ceremonial mysticism" is too brightly expressed (Markova, 1997, p. 237). Protestants rejected natural theology because of a particular emphasis on a fallen human nature.

From the point of view of the American researcher, "the only place in Christianity where the Creator's cult based on cosmological argument was systematically emphasized there is a Roman Catholic Church" (Markova, 1997, p. 237-238). Rather the special value of a cosmological argument in Catholic theological tradition from S. Yaki, undoubtedly, it is possible to agree, but with some reservation. The matter is that the natural theology started being developed actively by Foma Akvinsky at a turn of the XII-XIII century, till this period the status of cosmological argument of life of God in Roman Catholic religious thought was a bit different. However, we will consider this question more in details in the following paragraph. Here it is important to emphasize that, indeed, since the time of Akvinat the official doctrine of the Roman Catholic Church proving reliability with which the reason can comprehend existence of the Creator by studying the physical world developed.

It is no casual "The declaration I of the Vatican cathedral was supported with the reference to the well-known fragment from Pavel's message to Romans" (Markova, 1997, p. 239). Paul the Apostle writes to him: "Actually that it is possible to learn about God, is clear to them; because He made everything for this purpose. From the moment of creation of the world invisible realities, its eternal power, and the Deity, became visible, recognized in things that It created" (Rome 1: 19-20).

So, according to the American theologian and the historian of science, the modern European natural sciences could arise only in Christian culture because the Christianity is connected with belief in the personal, reasonable, transcendental Creator or the Legislator who created the rational world available to comprehension by human reason. In other words, the world is the objective and ordered reality comprehended by reason because the reason is too the ordered and objective creation of the same reasonable and perfect Creator. Here it should be noted that in the cosmological argument of Christian theology received a new embodiment the principle of identity of thinking and life in due time proved by Parmenides, which became the rationality basis as that. In the context of Christian creationism, this principle allowed to rehabilitate the sensual terrestrial world appearing in Parmenides doctrine as not true life about which the knowledge is impossible. Moreover, the natural theology as it was already noted, was actively developed in Catholic thought.

Further S. Yaki develops the initial thesis, marking out the features of the Universe directly connected with God Creator. To these characteristics of the Universe the knowledge about which submits the maintenance of the metaphysical bases of science, it carries the following:

1. "God creates the world, in this sense it is real.

2. At the beginning of the world - God Creator, who created the world voluntarily at the choice, and it means that the world could be and other, it is conditional.

3. The world, as well as each separate thing in the world, is specific, it such, other than any other possible world.

4. Its property not to be necessary follows from the previous two qualities of the world.

5. The world is causally caused and develops from the reason to a consequence, and the reason cannot turn out to be a consequence and vice versa as development is not cyclic.

6. God creates the world from anything" (Markova, 1997, p. 242).

The metaphysical regulations on features of the Universe formulated above following from Christian dogma are confirmed, according to S. Yaki, a number of discoveries of the XX century, for example, gravitational paradox of the infinite Universe, and also the theory of the extending Universe. The gravitational paradox according to which in infinitely uniform Universe consisting of stars, the total effect of gravitational attraction will be equal to zero as the attraction will be identical in all directions, raises doubts in the validity of scientific idea of the infinite uniform Universe, confirming the provision on uniqueness of the world, its uniqueness and dissimilarity in any other possible world. According to the theory of the extending Universe, the world has the beginning and the end that corresponds ideas of God Creator.

The modern researcher L. A. Markova, critically analyzing the concept of a ratio of science and S. Yaki's religion, pays attention, in particular, to a certain discrepancy between idea of uniqueness of the world on which the Christian theologian, to postulates of the classical science dealing with certain the average, unified objects, processes, and sizes, 
studying their quantitative characteristics places emphasis. The idea of identity is of particular importance already in nonclassical science. However S. Yaki interests a little, whether there are essential distinctions between classical natural sciences and science of the XX century.

Nevertheless, it is necessary to agree with the main thought of the Christian theologian that recognition of the features of the Universe directly connected with God Creator generates at the scientist confidence in reality of the reality surrounding it, its rational device and cognoscibility in the scientific ways and means. In other words, it is about those philosophical bases without which the science is impossible in general.

\section{The «Method from Conditions» of M. Weber - R. Merton}

If S. Yaki defends "the Catholic version" of genesis of classical science, the famous American sociologist R. Merton which externalist position we already concerned in one of the previous paragraphs, developing the line begun by $\mathrm{M}$. Weber connects emergence of science with Puritanism. M. Weber was the dependence of genesis of capitalism and the modern European science on Protestant values is shown (Vodenko, Tikhonovskova \& Ivanchenko, 2015). Formation of scientific norms as social Institute comes under the spotlight $P$. of Merton. Considering as fundamental signs of a new science experiment and its disciplinary as a form of the social organization of intellectual activity, Merton finds their sources in a way of life of Puritans. In this regard the modern American historian of theology and science E. M. Klaaren notes: "Merton defines the religious factor that had an impact on the development of new sciences as "the Puritan ethnos" and ... shows means of statistics that the considerable number of persons in these new areas (as well as among members of royal society) was made by Puritans whereas in the population of England they were minority" (Vodenko \& Tikhonovskova, 2015, p. 7-8).

Some peculiar features characterize the Puritan way of life, according to R. Merton. First, it is asceticism and the strict discipline connected with an embodiment in the life of Puritan doctrines of justification and predetermination. If according to idea of a justification successful utilitarian activity of the person aimed at glorification of God, the doctrine of predetermination directed to "good deeds" for the sake of the proof of God's chosen people. Secondly, "the imminent mysticism" unlike the "transcendental mysticism" typical for Catholicism is peculiar to puritanism (Klaaren, 1977, p. 452). Thirdly, one more important feature of a Puritan way of life, according to R. Merton, consisted in aspiration of Puritans to rationalism, i.e. praise of reason and refusal to oppose reason to belief.

From the point of view of the American sociologist of science, Puritan outlook and vital norms inspired new scientists to follow the professional discipline and to be engaged in experimenting. The experiment was a scientific expression of a practicality, activity, methodical Puritans. In other words, ethos puritans promoted a religious justification of occupations by sciences and, respectively, legitimation of scientific knowledge. Thus, R. Merton considers also considerable impact, which had on the process of formation of science from economy and trade, especially in the sphere of transport and military technology. They stimulated discoveries; the science was urged to satisfy requirements of their development.

In effect, R. Merton divides the externalist direction of understanding of genesis of science (J. Bernal, E. Tsilzel, etc.) bringing science with its rational and mechanistic vision of the world out of the rational bourgeois and economic relations becoming in the XVI-XVIII centuries. In opinions of representatives of the specified direction, formation of the bourgeois social and economic ties penetrated by spirit of rationalism of Modern times led to gradual weakening of religious, magic, animistic perception of the world and strengthening of rational ideas of the universe. Moreover, as the development of capitalist production demanded development of mechanics and mathematics, the picture of the world gained Rational Mechanics and Mathematics character, the thinking became rational. In works of externalist, dependence of formation and development of the modern European science on social and economic conditions of the arising capitalism, on growth of the cities and craft production, from interaction of practical experience of free handicraftsmen and abstract thinking of scientists, Protestant ethics and new norms of scientific research is investigated.

Thus, the science as productive force cannot realize the universality as, on the one hand, indeed, industrial revolution demanded development of technology and science, inquiries of production demand new knowledge that, really, brought to life science. However, on the other hand, not clear are reasons of changes in the outlook of people and transition from the medieval type of thinking to scientific. Now approach to the solution of the declared problem the complex: first, social and economic conditionality of science as development of the industry demands new scientific knowledge is not dismissed, secondly, searches of the answer to a question of the reasons for transformation of outlook of people from medieval type of thinking to the scientific do not stop.

R. Merton's attempt to rely only on Puritanism meets critical objections of E.M. Klaaren. In this regard, he writes: "The Merton perception of new science contains implicitly in its concept of Puritan ethnos, as conditions of the feasibility 
of new science. Such is his statement as if the discipline inherent in Puritan lifestyle generates new feeling of professionalism in science as in the experimental enterprise mainly. In my opinion, such data of new science to an experimentalism " - are noticed by the researcher - "is very limited. It leaves in a shadow greatness of intellectual tasks and the generating conceptual force hidden in new science and its respect for a reason" (Vodenko \& Tikhonovskova, 2015, p. 8).

However, similar objections, against an exaggeration simply of the interpreted experimentalism in new science, still in the late thirties the XX century A. Koyre who, in the context of criticism of positivistic interpretation of its character, fairly claimed stated that not the pragmatic empiricism, but the concept of mathematical realism is Descartes's concept, Galilee, and Plato.

Coming back to the analysis of methodological approach of R. Merton it is necessary to agree with E. M. Klaaren's conclusion that weakness of this approach consists in "an unjustified reduction as the analysis of conditions of emergence of science, and understanding of the science". "The explanation method from conditions" of the American sociologist of science, really, does not give the chance deeply to get into the modern European science, to understand why, for example, the understanding of space, the movements, the nature in general, etc. essentially changed. At the same time, demonstration of the relevance of social and religious conditions by R. Merton to the genesis of the new science was a certain achievement in the methodology of research of this process

\section{Methodology of "Absolute Metaphysical Prerequisites" of R. J. Collingwood}

In our opinion, more considerable potential the methodology of genesis and development of science presented in works of the 40th years of the XX century of the English historian and philosopher R. J. Collingwood possesses. In it a certain influence of the ideas of A. Koyre stated in "Etudes about Galilee," published in 1939 is felt.

The English researcher put forward the project so-called "metaphysics without ontology", or metaphysics as historical science about absolute prerequisites of scientific thinking. As ontologies, R. J. Collingwood did not agree with the treatment of metaphysics, considering that in modern conditions value of logical, but not ontological sense Aristotelean "the first philosophy" remains. In other words, Metaphysics is updated as the science of the highest kind of existence which types are ten categories. The maximum sort of life embraces everything existing; everything determines by itself, and there is no other than God. Therefore, Aristotle, as we know, calls the first philosophy also theology. In such interpretation, it becomes science about "absolute prerequisites" of scientific knowledge, and as they historically change, its task is disclosure of those metaphysical preconditions, which scientists accepted during the concrete historical periods.

The idea of "absolute prerequisites" which is put forward by the British researcher demands a certain explication. First, R. J. Collingwood pays attention to their unconscious character. Being based on all reasoning's and conclusions, they do not rely on consciously and are assumed implicitly as something silently implied, self-evident, concealed at heart. This basic feature distinguishes them, for example, from assumptions, which become in the act of a free choice, i.e. is quite conscious. Absolute prerequisites also unconsciously change, and it is possible to learn about their metamorphoses based on the historical analysis only subsequently. Also, these changes happen, extremely painfully as affect deep installations and belief of people, representing, according to R. D. Collingwood, not theoretical postulates, but beliefs. Beliefs, unlike ideas of the conceiving reason, are characterized, first, by ontological rootedness, i.e. indissoluble communication of the person with reality in the highest sense of this word. This deep communication arises as a result of them (beliefs) of people proves in all the integrity (without division into mind, feeling and will).

Many western philosophers of science of the XX century pay attention to the unconscious character of religious and metaphysical sources of the genesis of the modern European science. For example, A. Whitehead claims, "the belief in the possibility of science that arose even before the emergence of the modern scientific theory is unconscious derivative of medieval theology" (Petrov, 2000, p. 259). Thus, A. Whitehead emphasizes that, as belief understands "instinctive style of thinking, but the credo put into words is not simple". The famous modern Catholic researcher of religion and history of science $\mathrm{S}$. Yaki develop the same idea.

Let us notice that the problem of the possibility of not verbalized, premised knowledge is quite widely discussed also in modern domestic epistemology. However the unambiguous solution of this question is not found. Some authors develop the idea of the movement from not verbalized to verbalized forms of thought. So, M. K. Mamardashvili writes that from depth unconscious the "implicit" knowledge breaks to the sphere of consciousness as though "the third eye" which as the searchlight highlights directly essence of objective reality opens (Markova, 2000, p.63-65). As prerequisites for cognitive activity pays L. A. Mikeshin's attention to dual specifics of implicit personal knowledge: "Complexity of understanding of implicit knowledge is explained considerably by that, existing implicitly, it at the same time exists in the 
sphere of consciousness, not beyond its limits" (Mamardashvili, 1994, p. 146-157).

The second specific feature of the absolute prerequisite, from the point of view of R. D. Collingwood, its inclusiveness in some set of similar beliefs or "historical facts" which he calls "constellation" is. Let's notice that Klaaren, analyzing R. D. Collingwood's concept, calls a constellation of historical facts "the postulates functioning as contexts" (Klaaren, 1977, p. 450-451). He notes: "In R. D. Collingwood's methodology the concept of the postulates functioning as contexts acts as a decisive element. Though its approach is less rectilinear and harder, than a causal explanation, it at the same time and is more productive ... To put it briefly, Collingwood's approach offers a method of system historical research" (Vodenko \& Tikhonovskova, 2015, p. 11).

In our opinion, the term "postulates" in this case is not successful if to mean unconscious character of absolute prerequisites on which R. D. Collingwood while the concept "contexts" very precisely transfers their integrity synthetically character pays special attention. In this regard, the English researcher emphasizes: "It is impossible to give the answer to a question of what the particular person took for the absolute basis of this thought, a conclusion, situation, etc., pointing to one absolute prerequisite, but it is necessary to consider a complete constellation of the last" (Mikeshina, 1990, p. 66-67).

Comparing R. D. Collingwood and R. Merton's methodological approaches, Yu. Klaaren, the main advantage of the scheme of the first, fairly in our opinion, sees in detection of intellectual integrity, the general theological basis of an initial stage of Modern times, unlike R. Merton who is snatching out for an explanation of Genesis of science "the separate, taken out of a context, dissociated past events". The English philosopher and the historian find the beginnings of new scientific rationality in the uniform theology of the XVI-XVII centuries, which it allocates in thinking of real persons of that time, analyzing their intellectual activity. The part of this theological continuum, which the set of the operating postulates, is, Yu. Klaaren compares to T. Kuhn's paradigms in disciplinary matrixes.

At the same time, the domestic researcher M. K. Kissel fairly pays attention to essential difference of approach of R. D. Collingwood to a problem of dynamics of scientific knowledge from methodology of the author of the concept of scientific revolutions, which reflects influence culturally - O. Spengler and A. Toynbee's historical relativism. According to methodological approach of R. D. Collingwood, in development of scientific knowledge there is a transformation of one of "a constellation of prerequisites" into another, between them there is no impassable abyss (Collingwood, 1940, p. 287288). In this regard, the task of the researcher consists in getting into the sense of the beliefs existing and existing earlier. Then it has to compare the formulated religious credo with scientific thought of the corresponding historical era and then this credo and there will be a constellation of absolute prerequisites of science of this period in the same place (Collingwood, 1940, p. 287).

Such historical system of theoretical prerequisites of the genesis of the modern European natural sciences, according to R. J. Collingwood, the Christian doctrine of the Trinity doing the central part of Nicene Creed was, first. Following the tradition of the western divinity originating in the treatise Severina Boethius "How the Trinity is uniform God, but not three deities", gained development in scholasticism of Anselm, Abelard and other medieval thinkers, tradition which Hegel paid a tribute subsequently, the English researcher carries out a philosophical explication of a doctrine of the Trinity.

Actually, from Boethius times the western divinity proved the idea of the ternary development of the Divine being in God, which was caused by the Relations between Persons of the Trinity. Scholasticism allowed the possibility of a reasoning on a ratio of the Father, the Son and the Holy Spirit as dialectic triad. Thus, they used the category of the relation that is a category of Aristotelean logic. Subsequently Hegel interpreted the Trinity doctrine as bifurcation uniform on contrasts and return to uniform, but already mediated by this distinction: "God Father generates the Son as another. But in this another he beholds Himself, recognizes Himself and thus it is the Holy Spirit proceeding at the same time from the Father and the Son and reaching in the Christian community of the perfect reality and truth" ..." comes back to the unity which unity distinguished is, (Kissel, 1997, p. 21-22).

Commenting on Hegelian philosophic interpretation of a doctrine of the Trinity, the modern researcher Matyash T. P. concludes that the thesis about coincidence of the original doctrine of Christ to the doctrine of reason is the main thing in Hegel's doctrine. The German thinker, "living in Christian culture, knowing about secrets of Revelation, dared to resolve antinomy Trinities inherent in a doctrine by means of rational and speculative thinking, to consider God as the concept available to human reason and therefore defined" (Hegel, 1977, p. 72).

As well as Hegel, R. J. Collingwood treats Christianity as philosophy, and the highest purpose of the last sees in the intellectual knowledge of God. The emphasis on the intellectual maintenance of Christian religion, idea of its unity with philosophy was the methodological prerequisite of a philosophical explication of a doctrine of the Trinity, the English philosopher. It is significant that "Religion and philosophy" it begins the work with the following statement: "This book is result of attempt to consider the Christian creed not as dogma but as the critical solution of a philosophical problem ..." (Matyas, 2002, p. 13). 
The Trinity doctrine, from the point of view of the English philosopher considering it as a subject of a philosophical reflection, is some "a dialectics touchstone". Thus, it should be noted that the researcher not the theological problem of a trinity in its full value, and it occupies "the physio philosophical appendix setting coordinates of empirical research of nature". In this regard, R. J. Collingwood writes that representatives of a patristic "meant by belief in the Father (only in relation to procedure of natural sciences) the absolute prerequisite of existence of the world of the nature which always and it is indivisible one world. They meant the absolute prerequisite of by belief in the son that this one natural world is, nevertheless, a set of kingdoms of the nature, they meant the absolute prerequisite according to which, the world of the character of the structure is the world not simply things, but events or movements by belief in the Holy Spirit" (Mikeshina, 1990, p. 225-226).

In other words, church dogmatic persons of a form of God Father and the Son express idea of the most differentiated unity in terms, and a symbol of the Holy Spirit - idea of the universal movement, characteristic of the universe. Thus, Nicene Creed assumes a certain system of the metaphysical prerequisites forcing the world to think like unity of the variety got by the principle of the movement.

It's hard to disagree with the point of view of the English philosopher according to which the unity of variety and the movement represent the aprioristic principles, which are not found in the world by means of scientific empirical procedures, and are premised on it as something in advance set. In this regard, the modern researcher of creativity of Collingwood M. K. Kissel notes that in empirical reality "the unity is always given along with variety, and the unity is in effect, illusory, existing before mind ... will turn imaginary unity into the unit" (Collingwood, 1940, p. 292).

So, from the point of view of R. J. Collingwood, the physio philosophical Appendix of the Christian doctrine of the Trinity represents one of important "constellation of historic facts" or a certain system of historical metaphysical prerequisites of formation of the modern European science. At the same time, it should be noted that these prerequisites of very general character. They influence on characteristic for the scientist living in an initial stage of the Modern times cultivated in Christian culture, perception and understanding of the world as unities of the variety which is in the movement. However, it is not enough these prerequisites to explain Genesis of peculiar features of the classical science of Modern times. (We will remember that fact that, for example, Heraclitus and his followers in antiquity perceived the world similarly. Nevertheless, the experimental mathematical natural sciences were created more than through two thousand years).

In this regard, it should be noted that the significant place in works of the British researcher is allocated for consideration of more concrete, direct reason of this process, which he sees in the metaphysical provisions caused by specifics of medieval theological interpretation of a doctrine of Divine creation. To this conclusion R. J. Collingwood comes, making a start initially from the results received by I. Kant in his epistemology. The British researcher fairly claims that in "Criticism of pure reason" the great German thinker for the first time in the history of philosophy investigated cognitive practice of experimental mathematical natural sciences, but not process of knowledge in general.

Thus, from the point of view of R. J. Collingwood, Kant aprioristic forms of sensual contemplation are only relative prerequisites specifying conditions of application of mathematics to studying of natural phenomena, but the status of the absolute metaphysical prerequisite has the principle of applicability of mathematics to the world of the nature. As it was already noted above, Galilee and Descartes A. Koyre interpreted a support on this principle in science as a platonism in their views. At first sight can seem that the English researcher simply repeats the idea, profoundly reasonable A. Koyre. However, it not so. R. J. Collingwood goes further, revealing deep Christian theological sources of this principle.

According to the English researcher, "... the possibility of applied mathematics is one of the expressions in terms of the natural science of Christian belief that nature is the creation of an Almighty God ... Platonism of natural science of Renaissance is not in the bases Platonic, he fundamentally Christian" (Mikeshina, 1990, p. 253-254). R. J. Collingwood proves this idea as follows. In Platoon's doctrine, nature represents a kingdom of uncertainty and imperfection. In the Christian theology recognizing that, God is all-powerful and that the world of nature is the world of divine creation, it appears as a kingdom of accuracy and definiteness. "... Now began the business of belief to look at the world of nature as on an accuracy kingdom, but not approximations... A line is drawn or designed by God, and if God wished that it was a straight line, it would be a straight line. To tell that it not direct, means that it in accuracy something other. The scientist also has to define, what exactly it such" (Mikeshina, 1990, p. 252-253).

In this regard the prominent domestic historian and the philosopher of science M. K. Petrov pays attention to that fact that: "Collingwood found one of the postulates deciding for theology, belief of Modern times that God creator is allpowerful and, therefore, is occupied just by that and what it also is busy, but not something by another" (Klaaren, 1977, $p$. 449). Thus, the understanding of nature as divine creation changes the informative installation of the researcher. In this case questions "Why?", "What for?" become inappropriate, they are forced out more superficial and impersonal "How?".

From the point of view of the English researcher, with a Christian doctrine of divine creation according to which the 
nature is creation of Almighty and transcendental God, also the most important metaphysical prerequisite of the modern European science consisting in understanding of the character of cars are connected. The main distinction of antique and modern European scientific pictures of the world, which explains all other distinctions between them, consists in this feature. R. J. Collingwood fairly considers that "Greeks saw in nature reasonably self-coping whole whereas thinkers of the late Renaissance saw in this place of an Almighty God as something other, then the nature. Respectively, nature as whole was perceived by Greeks as an organism, and thinkers of the late Renaissance - as the car" (Vodenko \& Tikhonovskova, 2015, p. 13).

Therefore, the transcendental understanding of Christian God creator was some source of transformation of an image of nature of an organism in the mechanism. Thus if transcendence of God in Christian theology of an initial stage of Modern times or "the late Renaissance" (R. J. Collingwood) is correlated with mechanicalness of the nature, his pantheistical interpretation in antiquity corresponds to its harmony. It is hard to disagree with a chain of reasoning of the British researcher. Nevertheless, the similar discourse is resulted by a question of the following character: if transcendence of God is correlated with mechanicalness of the nature why the classical science arises only in the XVIXVII centuries, but not in an initial stage of existence of Christianity? Possibly, there are some aspects of a problem, which did not receive consideration in R. J. Collingwood's research. It will be necessary to address to them in one of the subsequent paragraphs.

Nevertheless, seeking for identification of a constellation of historic facts, the English philosopher finds double opposition of the nature: the nature mechanism resists not only to God as to the transcendental creator, but also the person to the transcendental being learning its means of reason. In this case, the reason cannot be considered included in nature, "conformal" with it, i.e. such what antique Greeks understood it. It is understood as a certain abstract means, which, comprehending nature, can manipulate it theoretically in mathematical formulas and practically in the experiment.

Thus the interpretation of the main categories of reason changes. In it the qualitative specification of objects affects rather quantitative, than: the movement is understood as a function of structure, but not as a certain tendency. The matter from primary and deprived of a form beginning becomes quantitative and organized generality of moving things (atoms); causality - formal and efficient, but not teleological; the laws existing in antique Space only in "the sublunary world" subordinate to themselves and "superlunary world".

Thus, R. J. Collingwood, investigating "a constellation of historical facts", or "the postulates functioning as contexts" in an initial stage of Modern times receives the following results. Theological shift from pantheism to theism was deep connected with cosmological transition from organic to a mechanistic view of the nature, and epistemological change of understanding of the nature of knowledge, transformation of ontologically reason, "conformal with the nature", in abstract reason, theoretically and almost manipulating it by means of specifically interpreted categories, mathematical formulas and experiment.

\section{Conclusion}

Therefore, we carried out the critical and reflexive comparative analysis of the main methodological ideas and approaches to a problem of Christian and philosophical sources of the modern European science. According to S. Yaki's concept, Christian Catholicism in which the Creator's cult based on the cosmological argument was systematically emphasized was the religion, which created optimum conditions for the development of science. However at all importance of cosmological argument for religious legitimation of knowledge of the nature "the Catholic version" of genesis of science is submitted insufficient for an experiment formation explanation as standards of substantiality and validity of scientific knowledge.

"The Protestant hypothesis" of R. Merton differs in an unjustified reduction of the analysis of religious conditions of emergence of science to features of a Puritan way of life, and data of specifics of science to simply to the interpreted experimentalism. Similar "the method from conditions" does not give the chance of an explanation of substantial transformations of the bases of antique and medieval science, which led to formation of the bases of the modern European natural sciences.

Unlike Merton approach, the method of "absolute metaphysical prerequisites" of R. J. Collingwood allows to reveal Christian theological "the postulates functioning as contexts" which being excremental in outlook of founders of classical science of Modern times, had impact on the content of their scientific ideas. At the same time at all operational advantages of methodology of R. J. Collingwood the fragmentariness of the historical, scientific, and theological material used by him defines a fragmentariness of the correlations of "absolute metaphysical prerequisites" revealed by it and the content of scientific ideas of founders of the modern European science.

In our opinion, the considered theoretic -methodological approaches do not mutual denial, and, on the contrary, 
complement each other. Their synthesis gives the chance to carry out a reconstruction of a theological context of formation of the science of the XVI-XVII centuries. This difficult context incorporated Christian to the dogmatic person, Catholic Thomistic doctrine of creation, rescue and ways knowledge of God, their forcible transformations, Protestant receptions of forcible ideas, which intertwined in very inconsistent way with phenomena of occult tradition.

\section{References}

Katasonov, V.N. (1997) Intellectualism and voluntarism // Philosophical and religious sources of science: collection of articles. M: Martis. Yaki, S. (1993) God and cosmology. M.: Allegro-Press.

Markova, L.A. (1997) Science and religion through the eyes of a Christian theologian S. Yaki // Philosophical and religious sources of science: collection of articles. M: Martis.

Vodenko, K.V. \& Tikhonovskova S.A. (2015) The Influence of Religious Values in the Development and Functioning of Economic Institutions // Mediterranean Journal of Social Sciences. Vol. 6, No. 3. Supplement 4. pp. 45-51.

Klaaren, E.M. (1977) Religion origions of modern science. Belief in Creation in 17th century thought. Grand Rapids, Michigan: Eerdmans.

Petrov, M.K. (2000) The history of the European cultural tradition and its problems. M.: ROSSPEN.

Markova, L.A. (2000) Science and religion: the problem of the border. St. Petersburg: Aletheia.

Mamardashvili, M.K. (1994) Classical and non-classical ideal of rationality. M.: Maze.

Mikeshina, L.A. (1990) Valuable background in the structure of scientific knowledge. M.: Prometheus.

Collingwood, R.G. (1940) An essay on Metaphysics. Oxford.

Kissel, M.A. (1997) Christian metaphysics as a factor in the formation and progress of modern science // Philosophical and religious sources of science: collection of articles. M: Martis.

Hegel, G. (1977) Encyclopedia of philosophical sciences: In 3. Vol. 3. M.: Misl.

Matyas, T.P. (2002) Hegel's dialectic and dogma of the Trinity Rational and non-rational // Rational and irrational: a collection of articles. Rostov-on-Don. pp. 66- 77.

Collingwood, R.G. (1994) Religion and Philosophy. Bristol.

Vodenko, K.V., Tikhonovskova S.A. \& Ivanchenko O.S. (2015) Trends and Prospects of Transformation of the Social Structure of the Russian Scientific Community // Mediterranean Journal of Social Sciences. Vol. 6, No. 3, June 2015. Supplement 6. pp. $313-$ 319. 